\title{
IRONIA E VISÃO NA NARRATIVA DE BALÃ̃O
}

\section{IRONY AND VISION IN BALAAM'S NARRATIVE}

Resumo: Toda ironia relacionada ao ofício profético na Bíblia Hebraica brota do contraste entre a percepção do profeta e a da audiência. Favorecido por um olhar privilegiado, o profeta, com destreza artística, expõe a visão limitada - portanto, inferior - de sua audiência. Como agente de ironia, o profeta desestabiliza sua audiência e lhe dá a capacidade de uma recomposição de visão. Contudo, em porções narrativas da Bíblia Hebraica, encontramos uma quebra de expectativa em relação a essa perspectiva diferenciada. Nem sempre o profeta é retratado como agente de ironia. Em algumas ocasiões, ele também é vítima. $O$ primeiro exemplo desse fenômeno é encontrado na narrativa de Balaão. A ruptura do padrão se dá na história de Balaão através da íntima relação entre ironia e visão. Através da análise literária da história de Balaão em sua forma final, o presente artigo visa a explorar a importância da relação entre ironia e visão na crítica a essa figura profética.

Palavras-chave: Ironia. Visão. Profeta. Balaão.

Astract: All irony related to the prophetic office in the Hebrew Bible stems from the contrast between the perception of the prophet and the audience. Gifted with a privileged view, the prophet, with artistic prowess, exposes the limited view of his audience. As an agent of irony, the prophet destabilizes his audience and gives them the ability to recompose their vision. However, in narrative portions of the Hebrew Bible we find a breach of expectation in relation to this distinct perspective. The prophet is not always portrayed as an agent of irony. On some occasions he is also a victim. The first example of this phenomenon is found in Balaam's narrative. The rupture of the pattern occurs in the story of Balaam through the intimate relationship between irony and vision. Through the literary analysis of Balaam's history in its final form, this article aims to explore the importance of the relationship between irony and vision in criticizing this prophetic figure.

Keywords: Irony. Vision. Prophet. Balaam.

\section{Introdução}

Em seu livro Irony and Meaning in the Hebrew Bible, Carolyn J. Sharp (2009, p. 125) observa:

O fenômeno da profecia bíblica pode ser interpretado como inerentemente irônico mesmo à parte das ironias particulares manejadas pelos profetas como armas em seu arsenal retórico ${ }^{1}$.

A afirmação de Sharp estabelece dois fatores fundamentais para a compreensão da relação entre o ofício profético e a ironia: (1) a natureza da profecia é essencialmente irônica; e, (2) quando "empunhada" pelos profetas, a ironia tem o valor de uma arma retórica.

\footnotetext{
* Professor no UNASP-ec. Mestre e Doutor em Estudos Judaicos pela Universidade de São Paulo. E-mail:

$<$ lucas.iglesias@unasp.edu.br>.

1 "The phenomenon of biblical prophecy may be interpreted as inherently ironic even apart from particular ironies that are wielded by prophets as weapons in their rhetorical arsenal." As citações de autores diversos aparecerão sempre em português, fruto da tradução do autor deste trabalho; porém, serão apresentadas em sua língua de origem em notas de rodapé.
} 
Na Bíblia Hebraica, o profeta é apresentado como aquele que fala autorizado pela divindade. Em outras palavras, o profeta "duplica a voz de Deus". Ao fazê-lo, manifesta uma perspectiva que ele nunca pode apreender completamente. "Assim diz o Senhor" é uma fórmula proferida por quem não é, de fato, o Senhor. Assim, a ironia profética pode ser evidenciada, inicialmente, como fruto da situação de o profeta estar "entre" Deus e a audiência, o povo. Sua condição de intermediação é de extrema tensão e contradição.

Jeremias, por exemplo, é instruído por Deus a viver isoladamente ( $\operatorname{Jr} 15: 17)$, não se casar nem ter filhos (Jr 16:1). Ele está desautorizado por Deus a se lamentar ou se alegrar junto a outros (Jr 16:1-9). Contudo, a despeito de seu estado de deslocamento, o profeta está constantemente inebriado de sentimento divino. Jeremias lamenta a situação de seu povo e intercede por Israel ( $\mathrm{Jr}$ 18:20), embora tenha sido ordenado a não interceder novamente (Jr 7:6; 14:11). Ainda que Jeremias esteja absorto pela discrepância entre a realidade de Israel e o ideal divino para o povo, ele reconhece que não está separado de sua audiência. As mesmas palavras dirigidas a ela são endereçadas a ele.

Inevitavelmente, a intermediação desestabiliza o profeta; afinal, ele profere palavras que não são suas. Paradoxalmente, contudo, encontram-se na Bíblia Hebraica enunciados divinos e humanos mesclados e, na maioria das vezes, sem marcadores de identificação do falante (ROFÉ, 1997, p. 56-57). Ao mesmo tempo em que, na Bíblia Hebraica, se destaca a importância essencial de se compreenderem as palavras de Deus e diferençá-las das humanas (Dt 13, 18; Jr 28), a intermediação ofusca essa forma binária de enxergar.

Em resumo, o profeta compartilha das esferas divina e humana. Palavras humanas e divinas são harmonizadas em um discurso fluido. Em seu próprio ato de elocução, a profecia figura como uma palavra ironicamente modificada, elusiva e "outra" em relação ao seu falante humano, como também em relação à sua fonte divina. Sobre esse paradoxo profético, Heschel (2001, p. xxii) observa: “[...] a incumbência profética é transmitir uma visão divina. Contudo, como pessoa, o profeta também é um ponto de vista. Ele discursa sobre a perspectiva divina conforme ela é compreendida a partir da perspectiva de sua própria situação"2.

Assim, a ironia em relação ao profeta engloba a concepção de visão. Em seu livro Prophetic Existence, André Neher (1969, p. 333) afirma: “A visão profética revela a essência das coisas. [...] Visão comum é designação. A visão profética é o dar sentido"3. . De acordo com Samuel A. Meier (2009, p. 43):

Tanto hōzeh como rō'eh são palavras hebraicas que significam "aquele que vê". Em todas as questões [...] quando Deus pergunta 'O que você vê?' notamos que a palavra empregada por Deus é precisamente a palavra $r \bar{o} ' e h$. Essa designação, 'aquele que vê', é tipicamente aplicada a indivíduos capazes de enxergar coisas que pessoas normais não são capazes. No caso de Jeremias e Amós, eles claramente veem em objetos do dia a dia um significado especial que escapa àquele que não possui o dom especial da visão ${ }^{4}$.

Em Amós 7:7-8, por exemplo, lê-se sobre essa visão distinta:

\footnotetext{
2 "[...] the prophet's task is to convey a divine view, yet as a person he is a point of view. He speaks from the perspective of God as perceived from the perspective of his own situation."

3 "The prophetic vision unveils the essence of the things. [...] Normal vision is designation. The prophetic vision is the giving of a sense."

4 "Hözeh and $r \bar{o}$ 'eh are both Hebrew words that mean 'one who sees'. In all of the questions [...] when God asks, 'What do you see?' we have noted that the Hebrew word God uses is precisely this word $r \bar{o}$ 'eh. This designation 'seer' is typically applied to individuals who are capable of seeing things that normal people cannot. In the case of Jeremiah and Amos, they clearly see in everyday objects a special significance which eludes the one who does not have the gift of special sight."
} 


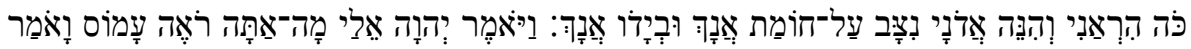

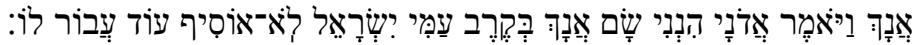

Mostrou-me também isto: eis que o Senhor estava sobre um muro levantado a prumo; e tinha um prumo na mão. O Senhor me disse: Que vês tu, Amós? Respondi: Um prumo. Então, me disse o Senhor: Eis que eu porei o prumo no meio do meu povo de Israel; e jamais passarei por ele ${ }^{5}$.

Amós é beneficiado com a habilidade especial de enxergar significância em objetos de outro modo ordinários. No diálogo contido na visão de Amós, o profeta poderia afirmar que via um muro, um homem com algo na mão ou um homem em um muro. Contudo, Amós atenta para o objeto mais relevante da visão, sem se distrair com componentes periféricos. Desse modo, Deus faz uso da percepção perspicaz do profeta como núcleo de desenvolvimento da mensagem do oráculo ${ }^{6}$.

Outro exemplo se pode encontrar no primeiro capítulo do livro de Jeremias ${ }^{7}$ :

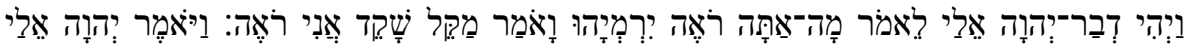

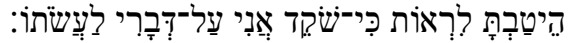

Veio ainda a palavra do Senhor, dizendo: Que vês tu, Jeremias? Respondi: Uma vara de amendoeira. Disse-me o Senhor: Viste bem, porque eu velo sobre a minha palavra para a cumprir (Jr 1:11-12).

Outra vez é dirigida a pergunta "que vês?" a um profeta. Assim como no caso de Amós, a resposta proferida aparenta ser simples. Contudo, as palavras daquele que é apto a enxergar de maneira distinta evidenciam a capacidade de pontuar os elementos indispensáveis da visão

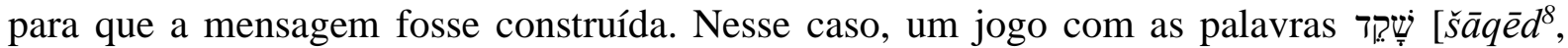

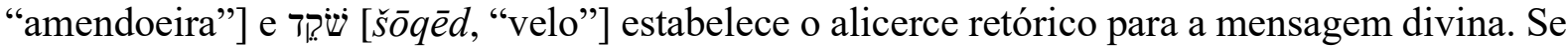
o objeto da visão fosse descrito simplesmente como um "pedaço de madeira" ou "graveto", a aplicação da visão escaparia à compreensão.

O profeta é o personagem capaz de enxergar a relevância específica de um evento, objeto ou comentário no que diz respeito ao que Deus intenciona realizar. Sua perspectiva deve estar em harmonia com a perspectiva divina.

Basicamente, toda ironia relacionada ao ofício profético na Bíblia Hebraica brota do contraste entre a percepção do profeta e a da audiência. Favorecido por um olhar privilegiado, o profeta, com destreza artística, expõe a visão limitada - portanto, inferior - de sua audiência. Como agente de ironia, o profeta desestabiliza sua audiência e lhe dá a capacidade de uma recomposição de visão.

Embora o profeta seja retratado como alguém dotado de uma percepção distinta, os diálogos que compõem as visões acima evidenciam o auxílio divino na decodificação da mensagem por meio da pergunta "que vês?" e na provisão de sentido. Conforme se verá adiante, mesmo quando a expectativa geral é de que o profeta seja um homem dotado de uma visão privilegiada, nem sempre isso ocorre. Afinal, ele é totalmente dependente da vontade divina.

\footnotetext{
5 Todas as referências ao texto bíblico em português foram extraídas da tradução Almeida Revista e Atualizada (1993). Caso outra versão seja utilizada em algum momento específico, será feita a menção no rodapé.

${ }^{6}$ A situação se repete em Amós 8:1-2.

${ }^{7}$ A situação se repete em Jeremias 1:13-14.

${ }^{8}$ As transliterações seguirão o padrão da obra: ALEXANDER, P. H. et al. (Eds.). The SBL Handbook of Style: for Ancient Near Eastern, Biblical, and Early Christian studies. Peabody: Hendrickson Publishers, 1999.
} 
Em algumas narrativas, inclusive, o profeta é retratado como vítima de ironia. Essa ironia emerge da relação entre a expectativa que se tem desse personagem e a realidade de visão que ele apresenta em determinadas situações, pois, sendo profeta, ele é, sobretudo, humano.

Assim, o presente artigo tem como objetivo examinar o primeiro episódio da Torá em que a visão distinta de um profeta, ou a expectativa em relação a essa visão, apresente episódios irônicos de disparidade. A abordagem metodológica que melhor se enquadra nos objetivos propostos na pesquisa é a análise literária dos textos bíblicos assim como são encontrados na Bíblia Hebraica, ou seja, no cânone judaico, uma vez que a presente pesquisa não focaliza a discussão sobre autoria, datação nem composição dos textos. Seguindo a abordagem de "Interpretação Total" proposta por Meir Weiss (1984, p. 1-47) ${ }^{9}$, os textos selecionados serão analisados a partir de suas próprias palavras, frases, imagens, sentenças, sequências e estrutura literária.

\section{A percepção profética na Torá}

Em The Anchor Yale Bible Dictionary, Schmitt (1992, p.482) argumenta que alguns personagens bíblicos de períodos anteriores são denominados profetas antes mesmo que a profecia existisse em seu sentido bíblico usual. A reflexão israelita sobre o período inicial na terra de Canaã indica que a profecia era parte fundamentalmente importante da herança cultural.

Abraão e Moisés são os precursores bíblicos desse ofício. Abraão é o primeiro

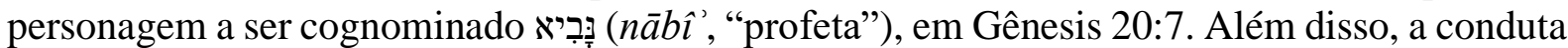
de Abraão é, em muitos aspectos, a de um וְּבְיא (NEHER, 1969, p.180). Abraão é chamado e enviado (Gênesis 12:1; 22:1). Encontramos aqui uma expressão que caracteriza Abraão e se constitui uma palavra-guia em sua vocação profética, רל? (lek-ləkāa, "vai-te"). O chamado de Abraão está relacionado a uma missão; ele é enviado para outras pessoas a fim de cumprir a tarefa divina.

Do mesmo modo que Abraão, Moisés, o segundo personagem bíblico a ser denominado נִּבְיא (nābî', "profeta"; Êxodo 7:1), combina aspectos de profetismo em seus relatos. De acordo com Sharp (2009b, p.19), Moisés se tornou conhecido por ser o paradigma de profeta devido à sua intimidade com Deus (Números 12:6-8). Ele é um intermediário entre Deus e o povo. Além disso, Moisés também é chamado e enviado para uma tarefa especial.

Apesar de Abraão e Moisés serem os principais nomes associados ao inicio do ofício profético, é dito, em Êxodo, que Arão agiria como profeta em relação a Moisés (Êxodo 7:1) quando eles se dirigissem ao Faraó. E, além disso, Miriam é denominada profetisa em Êxodo 15:20 (sem contar o questionamento da autoridade de Moisés em Números 12:1-15).

Ademais, ainda no Pentateuco, Deuteronômio parece pressupor a existência de profetas em um ambiente institucional. Há uma preocupação para que o povo saiba discernir as palavras de um verdadeiro profeta (Deuteronômio 13; 18).

Contudo, aparentemente nenhum desses personagens supracitados desponta em um episódio da Bíblia Hebraica que descreva a ironia da realidade de uma visão privilegiada ou a quebra dessa expectativa em relação ao ofício profético.

Basta lermos a Torá para constatar que Abraão e Moisés eram personagens que enxergavam de maneira diferenciada. Em Gênesis 22:4, após Deus ter pedido a Abraão que

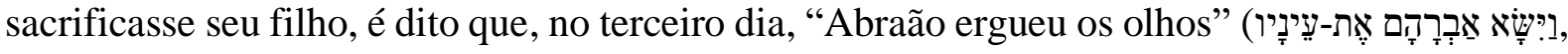

\footnotetext{
${ }^{9}$ No Second World Congress of Jewish Studies, em Jerusalém (julho de 1957), Meir Weiss sugeriu um método subsequentemente desenvolvido e descrito, seguindo uma sugestão de Martin Buber, como Interpretação Total (1984, p. 27). Embora ele não tenha se oposto ao estudo histórico de obras literárias, Weiss objetou à tendência de reduzir obras de literatura a meros documentos (1984, p. 66). Segundo ele (1984, p. 12), o primeiro dever do crítico literário é focar toda a sua atenção na obra literária em si, concentrando-se em suas qualidades intrínsecas.
} 
wayiśáa' ābrāhām 'et- 'ênāyw) e reconheceu o lugar como aquele que Deus havia designado para o sacrifício. Abraão enxerga de forma diferenciada, pois reconhece os sinais divinos. Se relacionarmos esse versículo com Oséias 6:2, os três dias parecem uma indicação simbólica do dia da salvação. E é justamente no terceiro dia que, após levar seu filho ao cume do monte e ser

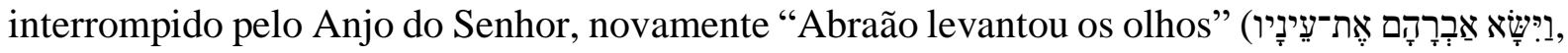
wayiśá ' ābrāhām 'et- 'ênāyw) e, dessa vez, vê um carneiro preso pelos chifres nos arbustos. Ele enxerga aquilo como uma resposta divina e o sacrifica em lugar do seu filho.

Moisés, aquele que vê a glória de Deus passar (Êxodo 33:17-23), também enxerga de maneira diferenciada. Em Números 11, encontramos talvez um exemplo, embora implícito, que mais se aproxima da disparidade irônica de visão que será examinada nesta pesquisa.

Após argumentar com Deus que sua carga de liderar o povo estava muito pesada (vv.1115), Moisés ouve de Deus que devia ajuntar setenta homens que dividissem as tarefas com ele. Moisés segue as instruções divinas, e, ao repousar o espírito sobre esses setenta, eles começam a profetizar (v.25). Contudo, dois homens haviam permanecido no acampamento, Eldade e Medade (v.26). Sobre eles também repousou o espírito, e eles também começaram a profetizar. Ao notar aquela manifestação no acampamento, um moço correu até Moisés e anunciou o que havia visto. Josué, servidor de Moisés, prontamente sugere que aquilo fosse interrompido. Entretanto, enxergando de uma perspectiva distinta, Moisés responde (v.29): "Tens ciúmes de mim? Tomara todo povo fosse profeta, que o Senhor lhes desse o seu Espírito!".

Porém, a intenção deste artigo não é analisar episódios em que um profeta simplesmente enxerga de forma diferenciada. O propósito é examinar a primeira situação da Torá em que a visão diferenciada do profeta, ou a expectativa em relação a uma visão diferenciada, proporciona episódios irônicos.

\section{Balaão e a expectativa da visão privilegiada}

O primeiro e mais nítido episódio de ironia relacionado à visão de um profeta na Bíblia Hebraica é o de Balaão, em Números 22:22-35. Como veremos na sequência, Balaão é contratado pelo rei de Moabe para amaldiçoar Israel. Assim, o exército moabita poderia repelir os invasores.

Na narrativa de Balaão, constatamos que persiste uma expectativa comum ao Antigo Oriente Médio de que o profeta é alguém dotado de uma capacidade inata ou conquistada. No entanto, como afirma Kaufmann (1989, p.87), "a faculdade do homem de Deus sempre depende da graça divina. Pela vontade de Deus, ele revela coisa ocultas, opera prodígios, cura, abençoa e amaldiçoa".

Enquanto a profecia no Antigo Oriente Médio é considerada derivada de uma fonte específica de poder mântico (um dom psíquico do profeta, natural ou adquirido), a concepção israelita não conhece nenhuma dessas fontes especificas de poder. Na Bíblia Hebraica, a profecia não é uma propriedade inerente.

Em narrativas bíblicas que envolvem profetas, a expectativa persistente do leitor é, muitas vezes, desfeita. O profeta é retratado, sim, como possuidor de uma percepção diferenciada, mas essa percepção é divinamente dependente. De acordo com Kaufmann (1989, p.97), “o espírito profético não está no profeta, mas 'cai sobre' ele. É um eflúvio divino que o toma e que pode abandoná-lo a qualquer momento".

Como veremos a seguir, é da interação entre a expectativa de percepção diferenciada e a dependência da revelação divina que brota grande parte da ironia bíblica.

Quando assenhorado da consciência divina, o profeta assume o papel de "ironista dissimulado", amplificando ou minimizando seu discurso. Por outro lado, algumas vezes, esse personagem, em sua humanidade falível, não tem plena consciência da situação em que se 
encontra e é surpreendido por ela, expandindo, assim, os contornos irônicos, uma vez que se espera dele algo que não demonstra ter.

No caso de Balaão, a ironia é ainda mais aguda, visto que sua falta de visão não é contraposta com a visão comum de sua audiência. Sua falta de percepção é assegurada em relação à visão elevada de um animal, uma jumenta.

\subsection{A jumenta}

Para se compreender o papel da jumenta na narrativa de Balaão, é de fundamental importância voltarmos ao início da Torá. Embora o discurso direto seja medular na definição da identidade humana na narrativa bíblica, observamos, em Gênesis $3^{10}$, que tal ocorrência é atribuída a um personagem não humano, a serpente. Dotada da capacidade de se expressar articuladamente com um humano, a serpente profere um discurso irônico de impacto fulcral na compreensão do trecho, quando examinado do ponto de vista intertextual - principalmente pelo fato de que, no discurso da serpente em Gênesis 3, variações sutis de discursos proferidos anteriormente irrompem como indicadores cruciais de intenções encobertas por parte do narrador ou do próprio personagem ${ }^{11}$.

Em apenas um outro episódio na Bíblia Hebraica, encontramos um animal beneficiado com a capacidade de se comunicar de maneira articulada, a jumenta de Balaão, em Números 22:22-35 ${ }^{12}$. De acordo com Savran (1994, pp. 34-35), "o episódio descrevendo a interação entre Balaão e sua jumenta é caracterizado por uma tensão entre repetição e transformação"13.

É digno de nota que tanto a jumenta quanto a serpente falam, surpreendentemente, de modo natural, sem seguir qualquer padrão de discurso com as fórmulas de personificação da natureza presentes em outros textos bíblicos (SAVRAN, 1994, pp.37-38). Essa habilidade não é explicada nem pelo narrador, nem pelo personagem, e, ainda assim, o texto nos impõe a aceitação inquestionável dessa capacidade humana outorgada, agora, a animais nessas narrativas. Na narrativa do Éden, a serpente e a mulher dialogam sobre a interpretação do significado correto das interdições divinas (Gênesis 2:16-17), como se esse fosse um tópico comum de discussão entre elas. Em Números 22, Balaão responde às palavras iniciais da jumenta ("Que te fiz eu, que me espancaste já três vezes?" - v.28) amaldiçoando-a e ameaçando-a de morte: "tivera eu uma espada na mão e, agora, te mataria" (22:29). Quando a jumenta tenta prover uma perspectiva diferente para amenizar a ira do seu dono ("Porventura, não sou a tua jumenta, em que toda vida cavalgaste até hoje? Acaso, tem sido o meu costume fazer assim contigo?" - v.30), a resposta monossilábica de Balaão parece indicar que ele havia sido persuadido por sua argumentação.

Embora, em ambos os textos, os animais conversem somente com uma pessoa (o que poderia indicar que, simultaneamente, estivessem "ouvindo alguma voz misteriosa"), o narrador, nas duas situações, ratifica a fala dos animais - no relato do Éden, através da maldição de Deus sobre a serpente em Gênesis 3:14 ("visto que isso fizeste [...]"); e, no relato de Balaão,

\footnotetext{
${ }^{10} \mathrm{O}$ primeiro episódio a apresentar ironia na Bíblia Hebraica. O discurso da serpente a Eva é irônico.

${ }^{11}$ Em Gênesis 3:1, por exemplo, ao dizer à mulher: "É assim que Deus disse: Não comereis de toda árvore do jardim?", a serpente deturpa o que Deus afirma em Gênesis 2:16-17, onde lemos: "De toda árvore do jardim comerás livremente, mas da árvore do conhecimento do bem e do mal não comerás; porque, no dia em que dela comeres, certamente morrerás". Nesse ponto, a sutil variação no discurso divino ratifica o epíteto da serpente como animal sagaz.

${ }^{12}$ É possível encontrar situações na Bíblia Hebraica de personificação metafórica (Salmo 19:1; Jó 38:7, 35) e parabólica (Juízes 9:8) da natureza. Entretanto, nesses casos, não nos deparamos com situações nítidas de discurso direto em que o ser não humano possui a capacidade de se expressar de forma estruturada e inteligente.

13 "The episode describing the interaction between Balaam and his ass itself is characterized by a tension between repetition and transformation."
} 
pela confirmação de percepção correta da mula por parte do anjo, em Números 22:31-33 (“a jumenta me viu e já três vezes se desviou de diante de mim [...]" - v.33).

Sendo assim, ainda que, na Bíblia Hebraica, a interferência animal no mundo humano de fala seja apresentada de maneira similar, o conteúdo dos discursos é contrastante. De maneira astuta, a serpente deturpa o comando divino de Gênesis 2:16-17, requerendo uma explanação por parte da mulher. O discurso da jumenta é direto e honesto. Seu propósito é clarear a confusão de Balaão, em vez de confundi-lo ainda mais.

Além disso, de acordo com Savran (1994, p.39), de grande importância é a questão sobre a fonte das habilidades de expressão articulada dos dois animais. Enquanto a serpente fala de acordo com si própria (nada é dito sobre ela, senão que era "sagaz"), no caso da jumenta, a capacidade de falar é, segundo o texto, divinamente proporcionada ("o Senhor fez falar a jumenta" - 22:28).

Na narrativa de Números 22:22-27, três vezes a jumenta se desvia, tentando evitar o anjo em seu caminho, transtorna seu dono e sofre com batidas. Na primeira vez, vv.22-23, a jumenta viu o Anjo do Senhor e se desviou do caminho, indo pelo campo. Como consequência, no v. 23, lemos: "Balaão espancou a jumenta para fazê-la retornar ao caminho".

Na segunda situação, vv. 24-25, "o Anjo do Senhor pôs-se numa vereda entre as vinhas, havendo um muro de um e outro lado" (v.24). Ao ver o ser divino, a jumenta "coseu-se contra o muro e comprimiu contra este o pé de Balaão" (v.25). Por conta disso, afirma o texto, Balaão "tornou a espancá-la" (v.25).

Por último, nos vv.26-27, o Anjo pôs-se num lugar estreito sem que a jumenta pudesse se desviar. Na sequência, o texto indica que, "vendo a jumenta o Anjo do Senhor, deixou-se cair debaixo de Balaão" (v.27). Em retribuição à ação da jumenta, Balaão se ira e a espanca com uma vara.

Observa-se, nessa sequência de eventos, uma ironia, que consiste em o narrador incluir na história uma espécie de retribuição na mesma medida. Por exemplo, o último dos três episódios de espancamento culmina com a conexão entre ira de Deus e a ira de Balaão. $\mathrm{O}$ narrador constrói a história de modo que, nesse ponto, o leitor seja capaz de relacionar as duas

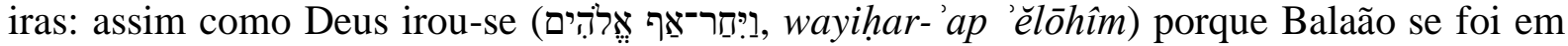

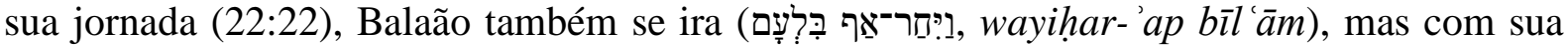
jumenta (22:27).

Outra característica comum a todas as formas de ironia e que também perpassa toda a sequência narrativa de Balaão é o contraste entre o aparente e o real. Constata-se que aquele que, comumente, exerce grande poder com suas palavras não é capaz de controlar sua própria jumenta com palavras. Embora o rei Balaque se dirija a Balaão afirmando: "porque sei que a quem tu abençoares será abençoado, e a quem tu amaldiçoares será amaldiçoado" (Números 22:6), o profeta carece do uso de uma vara. Ironicamente, o homem das palavras é reduzido à força bruta. Por outro lado, o animal bruto lhe ensina por meio das palavras.

Balaão é ridicularizado em sua descrição, pois não percebe que sua jumenta está falando. Ele dialoga com o animal como se uma jumenta falante representasse algo ordinário e natural. O animal, além de enxergar o anjo, dispõe de sua capacidade de comunicação para salvar tanto sua vida como a de seu dono.

No diálogo com a jumenta, o profeta é ridicularizado por parecer ignorante quanto às convenções apropriadas de discurso (MARCUS, 1995, 34). Após lermos, no v.28, que "o Senhor fez falar a jumenta [...]", Balaão é interpelado por ela, a qual questionava o porquê das chibatadas. Balaão responde: "porque zombaste de mim". Respondendo a Balaão, a jumenta elabora duas perguntas retóricas no v. 30: "Porventura, não sou tua jumenta, em que toda a tua vida cavalgaste até hoje? Acaso, tem sido o meu costume fazer isso contigo?”. Balaão responde: "não". Nesse ponto jaz o ridículo do diálogo. Perguntas retóricas não carecem de respostas, inclusive no texto bíblico. Não se espera respostas a perguntas como: "Acaso, é Israel escravo 
ou servo nascido em casa?" (Jeremias 2:14); "Poderão correr cavalos na rocha?” (Amós 6:12); ou “É razoável esta tua ira por causa da planta?" (Jonas 4:9). Desse modo, Balaão, ao responder às perguntas retóricas da jumenta, é retratado como ignorante quanto às convenções do discurso.

De acordo com Marcus (1995, pp.35-36), a resposta "não" de Balaão contribui para a ridicularização irônica do profeta, na medida em que ele simplesmente oferece uma única resposta a duas perguntas distintas, as quais exigem respostas distintas. Respondendo ao questionamento sobre aquilo ser ou não o costume da jumenta, a resposta "não" se enquadra corretamente. Contudo, quanto à primeira pergunta, "porventura, não sou tua jumenta, em que toda a tua vida cavalgaste até hoje?", a resposta "não" parece inapropriada. Enquanto a primeira pergunta é introduzida por הִּל (partícula interrogativa [hă] prefixada ao advérbio de negação לוֹ [lô", "não"]; "não sou [...]?"), a segunda é introduzida somente pela partícula interrogativa $\Xi(h \breve{a})$, que, no caso da narrativa em questão, reivindica uma resposta negativa.

$\mathrm{Na}$ Bíblia Hebraica, existem vários outros exemplos de perguntas retóricas duplas exigindo respostas distintas ${ }^{14}$. Todavia, é digno de nota que, em todos os outros casos, encontramos, em primeiro lugar, a partícula interrogativa e, em segundo lugar, a cláusula que une a partícula interrogativa ao advérbio de negação.

No mesmo livro que relata a narrativa de Balaão, encontramos outra ocorrência desse tipo de pergunta. Em Números 12:2, Miriam e Arão interrogam: "Porventura, tem falado o Senhor somente por Moisés?". De início, encontramos somente a partícula interrogativa em הִּר (hăraq, “somente?"), sem qualquer advérbio de negação. Porém, na pergunta seguinte, lemos: "Não tem falado também por nós?". Em vez de somente encontrarmos a partícula interrogativa, aqui encontramos הִלוֹא (hălô'). Assim, a queixa inicial recebe suporte da seguinte. A resposta esperada da primeira interrogação seria "não", enquanto a da segunda, "sim".

Dessa forma, no clímax da narrativa, em Números 22:28-35, a jumenta deixa de ser receptora passiva de punição e assume o papel de defensora articulada de suas próprias ações. Juntamente com a boca da jumenta, que se abre para a fala (22:28-30), uma experiência inusitada e surpreendente ocorre: são abertos os olhos de Balaão para uma nova percepção da realidade.

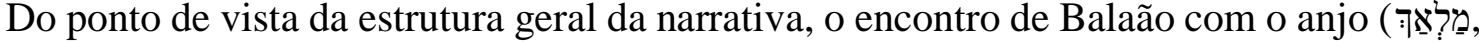

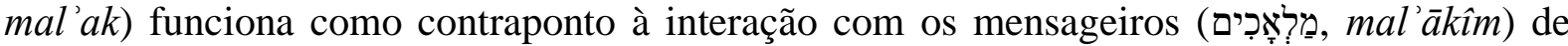
Balaque em Números 22:2-21. Da mesma forma que na relação entre Balaão e sua jumenta, Balaque guia Balaão a diferentes lugares, muito embora aquele que estava sendo guiado estivesse no controle. As acusações de má fé por parte de Balaque $(23: 11 ; 24: 10)$ espelham a acusação da jumenta sobre Balaão (22:28), sendo que a jumenta protesta pelo fato de Balaão tê-la ferido três vezes, e Balaque acusa Balaão de tê-lo enganado três vezes. Além disso, o texto evidencia um paralelo entre Balaão e a jumenta; visto que, da mesma forma que a jumenta é elevada do nível de um animal - caracterizado pela indiferença aparente com que cumpre sua função - a um modelo de obediência consciente, Balaão é transformado: ele passa de vidente mercenário a profeta de visão privilegiada.

\subsection{A visão}

Como já mencionado, a questão da visão é de suprema importância para o teor irônico da história. Logo no início, na primeira parte do capítulo, por iniciativa própria, Balaão consulta Deus à noite $(22: 8,19)$. Em Números 22:8, Balaão instrui os mensageiros a ficarem em sua

\footnotetext{
${ }^{14}$ Números 12:2; Deuteronômio 32:6; 2Samuel 2:26; 10:3; 2Reis 4:28; Isaías 36:21; Jeremias 3:1; 7:19; 22:15; 26:19; Miquéias 2:7; Ezequiel 17:10; 18:23, 29; Salmo 85:6-7; Esdras 9:14; 1Crônicas 19:3.
} 
casa e esperarem a resposta que o Senhor lhe traria. No v.19, já sabendo da resposta divina, Balaão novamente consulta a Deus, a fim de confirmá-la.

Em Números 22:22-35, no relato da viagem de Balaão com sua jumenta, uma reviravolta irônica ocorre quando Deus possibilita um encontro com o anjo à luz do dia, e Balaão, o vidente, não é capaz de perceber a sua presença. Ademais, a jumenta vê o anjo diante de si $(22: 23,25$, 27), enquanto Balaão, de respeitável reputação como vidente $(22: 6,9,20)$, somente o perceberá mais tarde. Em Números 22:31, lemos:

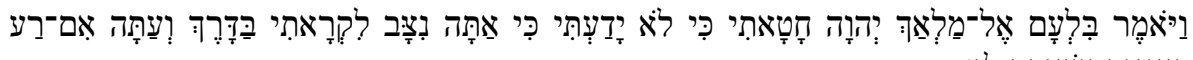

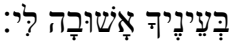

Então, o Senhor abriu os olhos a Balaão, ele viu o Anjo do Senhor, que estava no caminho, com a sua espada desembainhada na mão; pelo que inclinou a cabeça e prostrou-se com o rosto em terra.

Na sequência, em Números 22:34, lemos:

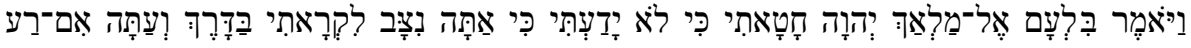

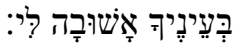

Então, Balaão disse ao Anjo do Senhor: Pequei, porque não soube que estavas neste caminho para te opores a mim; agora, se parecer mal aos teus olhos, voltarei.

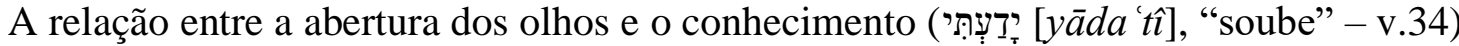
sublinha o fato de que, tal qual ocorrera com o homem e a mulher no jardim, também aqui uma mudança imediata é operada em Balaão - dessa vez, porém, não em direção à desobediência, mas uma mudança que o impele à obediência e ao reconhecimento do "erro", que era a tentativa de amaldiçoar Israel.

Assim como na narrativa de Gênesis 3, a jumenta exibe uma compreensão mais profunda da relação entre o humano e o divino do que sua contrapartida humana. E, além de revelar uma percepção apurada, seu conhecimento é exposto através de uma "educação" do humano envolvido.

Aparentemente, a discrepância entre uma visão humana ordinária, limitada a percepções superficiais, e uma visão "elevada", apta a captar as nuances de significados indisponíveis a qualquer um, é uma das marcas distintiva tanto de Gênesis 3 como de Números 22. Tanto na

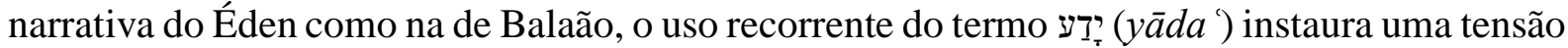
entre o que é aparente aos olhos e o que é conhecido. O fato de Adam e sua mulher comerem o fruto abre seus olhos a um conhecimento de natureza inesperada: "Abriram-se, então, os olhos

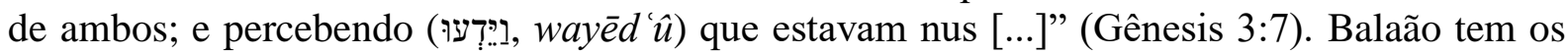
olhos descobertos e adquire uma nova percepção da realidade (Números 24:15,16).

Em hebraico, a primeira palavra a aparecer na história de Balaão (Números 22:2) é o verbo "ver", "o qual se torna apropriadamente, com alguns sinônimos, a palavra-guia nesta história sobre a natureza da profecia ou visão"15 (ALTER, 1981, p.105).

15 "which appropriately becomes, with some synonyms, the main Leitwort in this tale about the nature of prophecy or vision". 
Safren (1988, p.106) considera que o episódio específico de Balaão com a jumenta (Números 22:22-35) deve ser examinado em paralelo com a Akedah ${ }^{16}$. Para ele, a narrativa de Números foi moldada para evocar comparação e, ao mesmo tempo, contraste com o episódio de Abraão e Isaque (Gênesis 22:1-19), funcionando como uma narrativa espelhada ${ }^{17}$. Ele põe em relevo o fato de tanto Abraão como Balaão serem profetas. Segundo ele (1988, p.107), embora Balaão não seja chamado de profeta em Números 22, mas somente de adivinho (קטị,, qôsèm) em Josué 13:22, percebe-se que o papel de profeta se enquadra em seu ofício com base em seus oráculos ${ }^{18}$.

Além disso, para Safren (1988, p.106), a presença da palavra-chave "ver" (רָָָה $r \bar{a}$ 'a) nas narrativas de Gênesis 22 e Números 22 fortalece a relação entre os dois episódios. Na Akedah, a raiz do verbo ocorre cinco vezes (Gênesis 22:4, 8, 13, 14 [duas vezes]) com referência ao lugar do sacrifício (SAFREN, 1988, p.112). Em Números 22:22-35, a raiz também aparece cinco vezes: quatro delas relacionadas ao fato de a jumenta ver o anjo (Números 22:23, 25, 27 , 33) e uma vez (v.31) relacionada ao fato de que Balaão não o vê. Aquele que supostamente deveria ter a "visão do Todo-Poderoso" (Números 24:4) não é capaz de ver um anjo, que, por sua vez, é perfeitamente visível à jumenta. Na narrativa de Gênesis, "ver" aponta para o sublime; nesse episódio inicial de Números, "destaca o ridículo" 19 (SAFREN, 1988, p.112).

No relato das tentativas de amaldiçoar Israel, importa observar o procedimento gestual do profeta no inicio da história. Em Números 22:2, lemos que Balaque "viu [...] tudo que Israel fizera aos amorreus". O fato de Balaque ver "tudo que Israel fizera" é um prelúdio do que será reivindicado por parte do rei à Balaão. Duas vezes Balaque solicita ao profeta que veja Israel para 93maldiçoa-lo $(23: 13 ; 24: 1,2)$.

$\mathrm{O}$ ato de voltar-se para determinada direção ao pronunciar um oráculo está associado à expressão hostile orientation formula, cunhada por Hals (1989, p. 361). Essas fórmulas são comumente encontradas nos livros proféticos (especialmente em Ezequiel) através da ordem divina: "vira o teu rosto" (שָׁים

Block (1997, p. 35) é contundente ao declarar:

Os oráculos de Balaão constituem a melhor ilustração bíblica para o significado objetivo original da expressão em um contexto profético (Números 22-24). Três vezes, e em três lugares diferentes, sempre com Israel dentro da visão do profeta (Números 22:41; 23:13; 24:2), Balaão tentou proferir uma maldição sobre Israel. Na verdade, Números 23:13 sugere que a maldição não poderia ser propriamente proferida a não ser que Balaão tivesse um contato ótico com os objetos de sua maldição e que o Espírito de Deus não viria sobre ele até que o contato fosse feito. ${ }^{21}$

\footnotetext{
${ }^{16}$ De acordo com Sarna (1989, p.150), a narrativa de Gênesis 22:1-19 é comumente nomeada como Akedah por conta da raiz עִ ('āqad, "amarrar") no v.9. Em Gênesis 22, lemos o episódio em que é pedido a Abraão que sacrifique seu filho Isaque.

${ }^{17}$ Safren (1988, p.106), baseado nos estudos de Zakovitz, utiliza a expressão narrativa espelhada para tratar dos dois episódios. Segundo ele, a narrativa de Balaão e a jumenta deve ser estudada a partir da narrativa de Gênesis 22. Assim, o personagem refletido e suas ações são examinados como antítese da figura original e suas ações. Assim, o leitor, segundo ele, apreciando a afinidade entre o original e seu reflexo, capta novos insights ao avaliar os personagens.

${ }^{18}$ Além disso, tem-se o fato de que, segundo ele, na tradição judaica, Balaão é chamado de "profeta" (נְָָביא, nābî'). Cf. Baba Bathra 15b; Números Rabbah 20.1.

19 "underlines the ridiculous".

${ }^{20}$ Ezequiel 6:2; 13:17.

21 "the Balaam oracles provide the best biblical illustration of the original objective meaning of the expression in a prophetic context (Nm 22-24). Three times, and at three different locations, always with Israel within sight of the prophet (Nm 22:41; 23:13; 24:2), Balaam attempted to invoke a curse on Israel. Indeed, Nm 23:13 suggests that the curse could not be properly uttered unless Balaam had optical contact with the objects of the curse, and
} 
Em 22:41, Balaque toma a Balaão e o faz subir a Bamote-Baal, de onde o profeta tem uma visão "do alto" de Israel. De acordo com Milgron (1989, p.193), a expressão (bāmôt b $\bar{a}^{\prime} a l$ ) se refere a uma espécie de plataforma cúltica ao deus Baal. Para Balaque, ao posicionar o profeta naquele local, Israel estaria em desvantagem. Situar Balaão naquela plataforma era necessário para que o pronunciamento fosse eficaz.

Em Números 23-24, Balaão pronuncia quatro oráculos: Números 23:7-10; 23:18-24; 24:3-9; 24:15-19. De acordo com Milgrom (1989, p.467), muitos estudiosos consideram que as seções dos oráculos de Balaão constituem composições independentes das narrativas anteriores. Contudo, para ele (1989, p.468), através do desenvolvimento paralelo de temas idênticos tanto na poesia como na prosa, percebe-se que os capítulos 22-24 formam uma unidade orgânica.

Por exemplo, o primeiro oráculo faz referência ao relato da seção em prosa ao recordar que (1) o rei Balaque convocou Balaão de Arã para amaldiçoar Israel (23:7; 22:6); (2) Deus é quem determina se bênçãos ou maldições serão proferidas $(23: 8 ; 22: 12$, 24); (3) Balaão vê os israelitas do alto $(23: 9 ; 22: 41)$ e (4) os considera numerosos $(23: 10 ; 22: 5,11)$. O segundo oráculo alude à narrativa ao evidenciar que (1) o questionamento de Balaque é respondido imediatamente $(23: 17,18)$; (2) o Senhor não altera sua decisão, embora o rei o deseje (23:19; 22:13); (3) Israel é abençoado (23:20; 22:17). Os dois últimos oráculos ecoam a narrativa ao expor que (1) Balaão compõe seus oráculos divinamente inspirados (24:2b, 4, 16), visto que não há menção das palavras serem colocadas em sua boca $(23: 5 ; 12,16) ;(2)$ a revelação divina é direta $(24: 4,16 ; 24: 2)$; (3) os olhos do profeta estão abertos à revelação $(24: 4,16)$, o que, antes, representava um desafio a Balaão (22:31); e (4) ele vê o acampamento por completo (22:41; 24:5-6; 24:20) (MILGROM, 1989, p.467).

No primeiro oráculo (Números 23:7-10), ao tentar amaldiçoar Israel, o profeta profere que Deus não tinha intenção de amaldiçoá-lo. Nesse pronunciamento, há uma relação implícita entre ver Israel do alto e a percepção da situação do povo, enquanto nação isolada. No v.9, lemos:

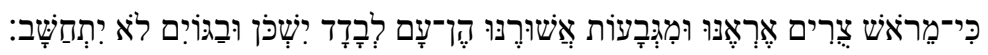

Pois do cimo das penhas, vejo Israel e dos outeiros o contemplo: eis que é povo que habita só e não será reputado entre as nações.

Ao ver Israel, Balaão reflete involuntariamente sobre o povo, ou seja, ele enxerga Israel, e não apenas o vê. Apesar de estar em Bamote-Baal, ao proferir o que Deus põe em sua boca (23:5), Balaão contempla de uma perspectiva divina; ele inicia um processo mais sofisticado de percepção.

Na sequência, Balaque espera que a disposição de Deus quanto a Israel mude ao reposicionar o profeta e oferecer novos sacrifícios (23:13-17). Contudo, o segundo oráculo (Números 23:18-24) evidencia que Deus não muda seu propósito. Além de abençoar Israel, Deus revela suas intenções através da profecia. Balaão reflete sobre a percepção de Deus em relação ao povo e, ao ver como Deus considera (vê) Israel, o profeta marcha em direção a essa percepção divina. Em Números 23:21, lemos:

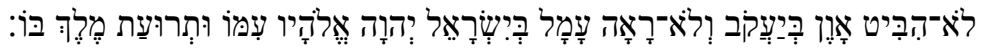

that the Spirit of God did not come upon him until that contact was made." 
Não viu iniquidade em Jacó, nem contemplou desventura em Israel; o Senhor, seu Deus, está com ele, no meio dele se ouvem aclamações ao seu rei.

Balaão afirma que Deus não contemplou desventura em Israel, permanecendo, assim, com seu povo. O profeta enxerga a conexão entre a vontade divina e suas palavras de bênção sobre o povo de Israel. O realce da visão na linguagem do início do v. 21 robustece a relação com o conhecimento.

Indignado com o segundo oráculo do profeta (23:25-30), Balaque afirma que o profeta não deveria abençoar nem amaldiçoar o povo de Israel (23:24). Balaão responde que está sendo somente o porta-voz divino. Balaque tenta novamente mudar a posição do profeta, pensando: "porventura, parecerá bem aos olhos de Deus que dali mo amaldiçoes" (23:27).

Contudo, dessa vez, é relatado explicitamente que Balaão toma consciência da intenção divina em abençoar Israel. Em Números 24:1, no terceiro oráculo, lemos:

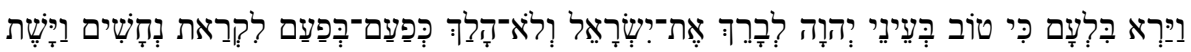

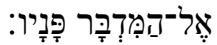

Vendo Balaão que bem parecia aos olhos do Senhor que abençoasse a Israel, não foi esta vez, como antes, ao encontro de agouros, mas levantou o rosto para o deserto.

Ao ver Israel, Balaão se conscientiza de que é bom aos olhos de Deus que esse povo receba bênçãos. Assim, no versículo seguinte, em vez da fórmula introdutória usual para os

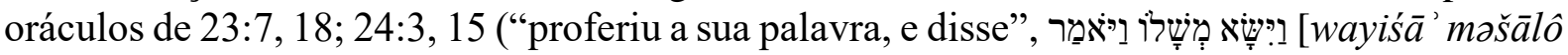
wayōmar]), lemos a expressão, de extrema relevância na Bíblia Hebraica, "erguer os olhos e

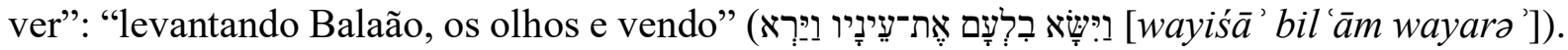
Essa declaração sobre a percepção de Balaão consolida o fato de que, agora, o profeta fala

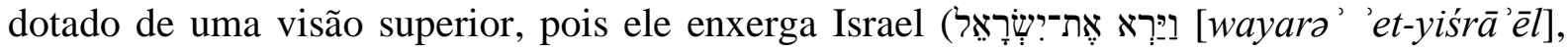
"vendo Israel" - v. 2) de maneira ampliada.

Tal percepção diferenciada se desdobra em três expressões presentes em Números 24:3,4:

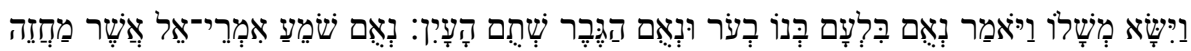

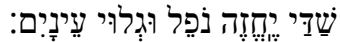

Proferiu a sua palavra e disse: Palavra de Balaão, filho de Beor, palavras do homem de olhos abertos; palavra daquele que ouve os ditos de Deus, o que tem a visão do Todo-Poderoso e prostra-se, porém, de olhos abertos.

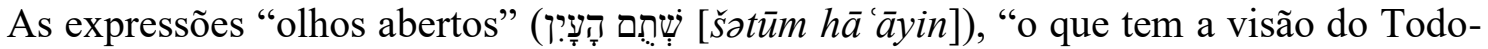

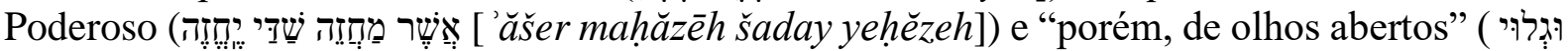

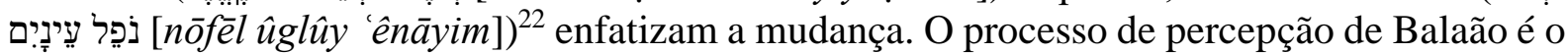
da descoberta inesperada e involuntária. Ao erguer os olhos, Balaão não pode senão abençoar Israel. Enquanto, nos dois primeiros oráculos, basicamente, a bênção se restringia à última linha do poema, no terceiro, todo o oráculo apresenta bênçãos a Israel (SAVRAN, 1994, p.48).

\footnotetext{
${ }^{22}$ A última das três expressões ecoa diretamente a linguagem de Números 22:31, quando os olhos de Balaão são abertos e ele pode ver o anjo em seu caminho.
} 
Por fim, no quarto oráculo (Números 24:15-19), as três expressões proferidas em 23:34 se repetem, mas com um adendo significativo:

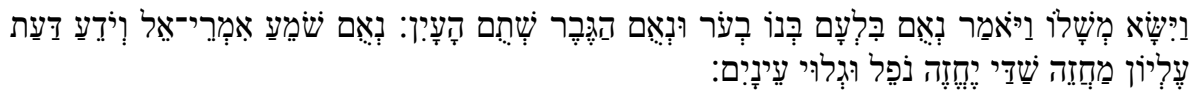

Então, proferiu a sua palavra e disse: Palavra de Balaão, filho de Beor, palavras do homem de olhos abertos; palavra daquele que ouve os ditos de Deus e sabe a ciência do Altíssimo; daquele que tem a visão do TodoPoderoso e prostra-se, porém, de olhos abertos.

No quarto oráculo de Balaão, vemos o acréscimo da expressão "sabe a ciência do

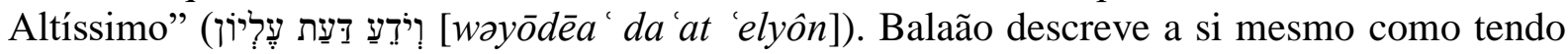
alcançado o nível mais alto possível de percepção, no qual seu olhar está em harmonia com o "olhar de Deus". Aqui, a relação entre visão e conhecimento está configurada como uma afirmação.

\section{Conclusão}

Nesse primeiro episódio da Bíblia Hebraica em que é quebrada a expectativa em relação à figura do profeta, notamos a importância da ironia. A ironia que nasce da quebra de expectativa quanto à visão distinta do profeta é proporcionada pelo narrador onisciente que a tudo tem acesso. Balaão não é capaz de enxergar o que uma jumenta enxerga.

O narrador bíblico e Deus, além de serem correspondentes na narrativa, possuem uma relação de fluxo de autoridade: da primeira ordem (divina) para a segunda ordem (derivativa, mas não menos importante). Com efeito, “[...] a própria escolha de inventar um narrador onisciente serve para o propósito de encenar e glorificar um Deus onisciente"23 (STERNBERG, 1987, p. 89).

Devido ao fenômeno de onisciência do narrador bíblico, o profeta é comumente vulnerabilizado nas narrativas. Locado em um nível superior ao dos personagens e leitores, o narrador é o único capaz de retratar o profeta como possuidor dessa visão distinta. Enxergando a partir de uma perspectiva distinta da audiência, o narrador é o único apto a apontar as ironias oriundas da discrepância entre a visão comum e a visão privilegiada. O narrador é onisciente, mas o profeta não. Assim, é na prosa que se recorda que o profeta é um ser humano como todos os outros. E, por mais que o enxergue de maneira extraordinária, o leitor é lembrado de que essa qualidade depende incondicionalmente do favor divino. A ironia oriunda da ruptura da expectativa sobre a visão distinta do profeta é proporcionada pelo narrador, que a tudo tem acesso.

\section{Referências Bibliográficas}

ALEXANDER, Patrick H. et al. (Eds.). The SBL Handbook of Style: for Ancient Near Eastern, Biblical, and Early Christian studies. Peabody: Hendrickson Publishers, 1999.

\footnotetext{
23 "The very choice to devise an omniscient narrator serves the purpose of staging and glorifying an omniscient God."
} 
ALTER, Robert. The Art of Biblical Narrative. New York, NY: Basic Books, 1981.

Bíblia. Traduzida por João Ferreira de Almeida. Revista e Atualizada no Brasil. 2 ed. Barueri: Sociedade Bíblia do Brasil, 1999.

BLOCK, Daniel I. The Book of Ezekiel: Chapters 1-24. Grand Rapids, MI: Eerdmans, 1997.

HALS, Ronald M. The Forms of the Old Testament Literature: Ezekiel. Grand Rapids, MI: Eerdmans, v. XIX, 1989.

HESCHEL, Abraham J. The Prophets. New York, NY: Perennial Classics, 2001.

KAUFMANN, Y. A religião de Israel. São Paulo, SP: Editora Perspectiva, 1989.

KÖEHLER, L. et al. The Hebrew and Aramaic Lexicon of the Old Testament. Leiden: E. J. Brill, 1994-2000. Electronic edition.

MARCUS, David. From Balaam to Jonah: Anti-prophetic Satire in the Hebrew Bible (Brown Judaic Studies, n.301). Atlanta, GA: Scholars Press, 1995.

MEIER, Samuel A. Themes and Transformations in Old Testament Prophecy. Downers Grove: IVP Academic, 2009.

MILGROM, Jacob. The JPS Torah Commentary: Numbers. Philadelphia, PA: The Jewish Publication Society, 1989.

NEHER, André. The Prophetic Existence: A new analysis of The Prophets of the Old Testament. London: Thomas Yoseloff Ltd., 1969.

ROFÉ, Alexander. Introduction to the Prophetic Literature. Sheffield: Sheffield Academic Press, 1997.

SAFREN, J. D. "Balaam and Abraham". Vetus Testamentum, Vol. 38, Fasc. 1 (Jan., 1988), pp. 105-113.

SARNA, Nahum. The JPS Torah Commentary: Genesis. Philadelphia, PA: The Jewish Publication Society, 1989.

SAVRAN, George. "Beastly Speech: Intertextuality, Balaam's Ass and the Garden of Eden". Journal for the Study of the Old Testament. 64 (1994): 39.

SCHMITT, John J. Prophecy: Preexilic Hebrew Prophecy. In D. N. Freedman (Org.), The Anchor Yale Bible Dictionary (Vol. 5). New York: Doubleday, 1992, pp.482-489.

SHARP. Carolyn J., Irony and Meaning in the Hebrew Bible. Bloomington, IN: Indiana University Press, 2009.

STERNBERG, Meir. The poetics of the Biblical Narrative: ideological literature and the drama of reading. Bloomington: Indiana University Press, 1987.

WEISS, Meir. The Bible from Within. Jerusalem: The Magnes Press, 1984 